\title{
Multiple Views of the Glimmerglass in the Coopers' Otsego Lake Writings
}

\author{
Jing-Dong Zhong ${ }^{1}$ \\ ${ }^{1}$ English Faculty, Zhejiang Yuexiu University of Foreign Languages, Shaoxing, China \\ Correspondence: Jing-Dong Zhong, English Faculty, Zhejiang Yuexiu University of Foreign Languages, \\ Shaoxing, China. E-mail: 1755516968@qq.com
}

Received: August 9, 2019 Accepted: September 11, 2019 Online Published: November 14, 2019

doi:10.5539/ells.v9n4p21 URL: https://doi.org/10.5539/ells.v9n4p21

\begin{abstract}
Focusing on Otsego Lake, named as the Glimmerglass, this paper attempts to offer a further insight into the mode of perceiving and imagining the lake scenery. To get a full picture, the case studies include both fictional and non-fictional works, concerning three generations' male and female perspectives from James Fenimore Cooper, his father and his eldest daughter. The specific study adopts a method of being "descriptive and phonomenological" (Hodder, 2001, p. 23). By citing and juxtaposing relative writings, it tries to relive the multiple views of the Glimmerglass and examine particularly the person's immediate responses to the lake, which might demonstrate the decisive transformation of his or her consciousness. The study finds that although multiple views of a lake are involved in perceiving and imagining its scenery, which combine to make a full picture and bring in rich experiences, the close-up views preferred in The Deerslayer can denote more immediate responses to the lakesape, and accordingly with more engagement and even immersion in the environment an encounter of a lake might become an insider, who, with a "sympathy for mystic states" (Hodder, 2001, p. 21) might regain a sense of homecoming or dwelling.
\end{abstract}

Keywords: Otsego Lake, James Fenimore Cooper, author lake country, prospect views, close-up views

\section{Introduction}

On a summer evening in 1840, riding back from his farm overlooking Otsego Lake, James Fenimore Cooper (1789-1851), now a middle-aged man, suddenly stopped "as an opening in the wood revealed a sweet view of the lake," and his eyes "rested a moment on the water, with that expression of abstracted, poetical thought," then, turning to his daughter Susan Fenimore Cooper (1813-1894), this writer exclaimed: "I must write one more book, dearie, about our little lake" (Cooper, 1861, p. 322, emphasis added). This lake "has been closely examined by three generations of the same family" (Cooper, 1968, p. xxxiii) - the Coopers. Thus, it becomes "our" lake, which is of great significance for Cooper. Denying "all of the regions of his [Cooper's] imagination are of equal weight and carry equivalent significance," Thomas L. Philbrick rightly considers the description of this geometry of imagination "as a series of concentric circles; within the inmost ring is a lake, Otsego" (1979, pp. 7-14). Cooper's "phenomenal visual memory" (MacDougal, 1989, p. 9) enabled him to recreate the lake country and before that summer evening he had already written several books concerning it. Anyhow, it is this "one more" book-The Deerslayer (1841), in which Otsego Lake is named as the Glimmerglass for the first time, that is given more importance to, for in this novel the lake itself "moves to center stage" (MacDougal, 1989, p. 73) and the relative descriptions make "Cooperstown's Lake Otsego world famous" (MacDougal, 1998).

It is said that a Russian sea captain in the Black Sea once wrote to inquire "how well Cooperstown was preserving the beauty of Lake Otsego that Cooper's writings had imprinted on his consciousness" (MacDougal, 1998, emphasis added). To comprehend the imprinting mechanism of such lake writings, especially The Deerslayer, one needs to do further studies, though some research assignments have already been undertaken from a variety of perspectives such as space poetics and ecosemiotics. This paper attempts to offer a further insight into the mode of perceiving and imagining the lake scenery. The study will start with examining the concept of author lake country and its possible general features. Then, to get a full picture, the case studies include both fictional and non-fictional works, concerning three generations' male and female perspectives from James Fenimore Cooper, his father and his eldest daughter. The specific study will adopt a method of being "descriptive and phonomenological" (Hodder, 2001, p. 23). By citing and juxtaposing relative writings, it will try 
to relive the multiple views of the Glimmerglass and examine particularly the person's immediate responses to the lake, which might demonstrate the decisive transformation of his or her consciousness.

\section{Author Lake Country and Otsego Lake}

"Places associated with writers and their writings," which are thus named as literary landscape or author country, "have attracted special attention since ancient times" (Watson, 2009, p. 14). The desire to visit such places gave rise to literary tourism, which was rooted in a sixteenth-century memorial culture dedicated to Italian poet Francesco Petrarch (1304-1374) and then "emerged in the Anglophone world beginning in the latter half of the eighteenth century and developed during the nineteenth century into a significant cultural phenomenon" (Hess, 2016, p. 175), and has gained ever-increasing popularity in contemporary society. On the literary tourist map, the type of author lake country is always prominent, which demonstrates a continuing force in shaping and refreshing a literary Mecca and thus deserves a continuous concern. For instance, as far as an Anglo-American literature fans or even a beginning learner is concerned, the mention of a literary tourist destination frequently brings in the lake images of "Wordsworthshire" and "Thoreau Country", and these two writers involved have already "established them as founding figures for the British and American nature writing traditions" (Hess, 2016, p. 177) respectively.

How the lake writings by the writers like Wordsworth and Thoreau demonstrate such "a continuing force" has been so long intensively examined. As one of the devoted scholars, Scott Hess argues that through locating the author in "an eternally present nature, imagined as outside of human society and history," such natural landscapes offer "a particular intense experience of communing with the author in and through nature, uninterrupted by mediating characters or social fictions," an opportunity to step into "a transcendent sphere" (2016, p. 176), gaining the sense of unity. What Hess chooses as the model of such landscapes is author lake country, for the reflecting and blending properties of a small lake make it an ideal place to enter the spiritual state mentioned above. Appreciating Jacqueline Labbe's statement that "the tourist who reads and follows Wordsworth's suggestions" will "see through Wordsworth's eyes," Hess further points out that viewing and responding to nature in these ways the reader or visitor "also ideally attempts to reproduce the poet's own original state of consciousness" (2012, p. 73). For instance, in Home at Grasmere the poet first requests us to throw the eye sights upward to "all the distant grove" which "rises to to the summit of the steep" and then guides us to the bright inverted "universal imagery" in the still lake, where "The boundary lost, the line invisible/That parts the image from reality," so as to gain a sense of homecoming or dwelling with him (cited by Spector, 1977, p. 98).

In the case of reading Thoreau's lake writings, Alan D. Hodder emphasizes a "sympathy for mystic states" (2001, p. 21) experienced by Thoreau, and thus gives "long and fascinating citations" from Walden to let the subjects "speak for themselves" $(2001$, p. 25) in a reflecting mode, which might convincingly reveal "a feature of natures functioning that Thoreau found endlessly suggestive, even consoling" (2001, p. 192). In fact, this mode or "natures functioning" is generally associated the "mirror imagery" of a lake, which "symbolize a harmonious relationship between the mind and the world based on the reflecting water and the reflective mind" (Spector, 1977, p. 85). If as Meister Eckhart states, "The eye and the soul are also mirrors, and whatever stands in front of them appear within them" (cited by Novak, 2007, p. 36), these mirrors should be clear and calm enough. The unruffled mirror of a small lake might help the mind to enter such a state, for "While employed on its shores, or in sailing upon its bosom, the traveller is insensibly led into an habitual, and irresistible, consciousness of singular salubrity, sweetness, and elegance" (Twight, 1969, p. 247, emphasis added). And, "When the mind has a little recovered it's tone," as William Gilpin points out, "it feels a new pleasure in examining more minutely the several pictureque ingredients," including "the stillness, and purity of the air - the strong lights and shades - the tints upon the mounntains - the polish of the lake" and so on (2013, p. 125). The views of these waterscapes in conjunction with light might even offer "awe, emotional transport, and the desire to worship that which transcends humanity" (Barbour, 2004, p. 130). No less than Walden and the English lakes, Otsego Lake can also be used to assist such "spiritual transmutation" (Novak, 2007, p. 37), after all, it has another name of the Glimmerglass.

This lake is located in the Central Region of New York State. Like other glacial lakes which "were gouged out by glaciers during the last great Ice Age," this lake is also "deep and steep-banked, so that its waters reflect the changing sky and clouds, the surrounding hills, and the overhanging trees that still line much of its shoreline" (MacDougal, 1989, p. 70). Fed by streams from the north, and by many springs, the lake is the source of the Susquehanna River while it is also geologically related to the Finger Lakes but is not counted among them, for it is situated at a higher elevation than them. Perhaps one more factor of making the difference lies in its closer association with the Indian culture, since the very name Otsego itself comes from a Mohawk or Oneida word 
which means "place of the rock," referring to the large boulder near the lake's outlet, today known as "Council Rock" that is believed to have been once a meeting place for Native Americans before the American Revolutionary War.

Until the early nineteenth-century, "A bird's-eye view of the whole region east of the Mississippi must then have offered one vast expanse of woods, relieved by a comparatively narrow fringe of cultivation along the sea, dotted by glittering surfaces of lakes" such as Otsego Lake, and "intersected by the waving lines of river" such as the Hudson River (Cooper, 1993, p. 16, hereafter only the page number of this book referred to in parenthetical citations). This region, still chiefly dwelt by Woodland Indians, was like "a vast picture of solemn solitude" with some prominent spots in the contrasting colors of the dark forest and the luminous water face. It is no hard to imagine that a transcendent, religious or at least joyful feeling would be aroused in the heart of a person encountering such a spot, who just took a journey filled with "toils and dangers of the wilderness" (Cooper, 2005, p. 6).

Among the spots concerning such encounters, the panoramic view of the lake and village, seen from the summit of Mount Vision on the eastern shore, held for the Cooper family great importance. It was here that Cooper's father William first glimpsed the lake in 1785, some Cooper's fictional protagonists caught the first sight of it, and Cooper's eldest daughter Susan surveyed the whole lakeland to prepare for her full picture of the lake country. The next section will discuss such prospect views.

\section{The Prospect Views of the Glimmerglass in the Coopers' Otsego Lake Writings}

One day in the fall of 1785 , land speculator William Cooper urged his horse up a steep wooded ridge in central New York, which afforded an excellent prospect wisth an increase in height. Then, if the sunlight was strong that day, Lake Otsego, glinting between the twin ridges unquestionably, glowed for his eyes and he let out a cry: "With a slight wind ruffling its surface, the water may even have glimmered like shards of glass. How could he not be ravished by what he saw?" (cited by Franklin, 2007, p. 2, emphasis added) These first impressions turned out to be a template of the lake and its surroundings, which would be transferred into the minds and works of the next generations of the Cooper family. In James Cooper's novel The Pioneers (1826), this similar scene is recalled by Judge Temple of Templeton, for whom William Cooper is the prototype:

... [I] rode to the summit of the mountain, that I have since called Mount Vision; for the sight that there met my eyes seemed to me as the deceptions of a dream... The lake lay, like a mirror of glass.... Not the vestige of man could I trace... from my elevated observatory. No clearing, no hut, none of the winding roads that are now to be seen, were there; nothing but mountains rising behind mountains, the valley, with its surface of branches... (Cooper, 2007, pp. 236-237, emphasis added)

Why the sight of "dream" at the summit of the mountain named by William Cooper makes Judge Temple so "ravished" as well? This can be explained from two aspects: first, they grasps the particular feature of the Otsego lake - being "glimmered like," "like a mirror of glass." The same feature strikes the protagonist of The Deerslayer, and it is no wonder that he naturally names it as the Glimmerglass, which is still widely and formally used today; second, perhaps more importantly, they gains a prospect view. "The love of prospect," as Humphry Repton states, "seems a natural propensity, an inherent passion of the mind" (cited by Nevius, 1976, p. 27). Anyhow, this lake-associated vantage point is so familiar that in the initial parts of chapter three in The Pioneers (1826), even the horses "seemed to know by instinct that the journey was nearly ended." Even if it is in the winter, there is no difficulty for the traveller in gaining a sense of intimacy, for:

Immediately beneath them lay a seeming plain, glittering without in equality, and buried in mountains. The latter were precipitous... and chiefly in forest. Here and there the hills fell away in long, low points, and broke the sameness of the outline, or setting to the long and wide field of snow, which... resembled so much spotless cloud settled to the earth... immediately under the feet of our travellers, alone showed by its rippling surface, and the vapors which exhaled from it, that what at first might seem a plain was one of the mountain lakes, locked in the frosts of winter... The banks of this lovely basin, at its outlet, or southern end, were steep, but not high; and in that direction the land continued... a narrow but graceful valley... Immediately on the bank of the lake and at its foot, stood the village of Templeton. (Cooper, 2007, pp. 34-36, emphasis added)

This prospect view of Otsego Lake portrays thoroughly "a pattern of integrated communities" (Siewers, 2009) which consists of mountains, trees, hills, a valley, a village and a lake in the winter, whose close association is denoted by the repetition of three items of "immediately". It is an ecological picture of lake dwelling, and a more living version in the spring is composed in another Cooper's Lake Country novel, Home as Found (1838), when the Effinghams and others leave New York City for a country life and finally reaches the same spot at the summit 
of the Mount Vision, they see

Hundreds of feet beneath them, directly in front, and stretching leagues to the right, was a lake embedded in woods and hills. On the side next the travellers, a fringe of forest broke the line of water; tree tops that intercepted the view of the shores; and on the other, high broken hills, or low mountains rather, that were covered with farms, beautifully relieved by patches of wood, in a way to resemble the scenery of $a$ vast park... Bays and points added to the exquisite outline of the glassy lake on this shore... A wide, deep, even valley, commenced at the southern end of the lake... and stretched away south, until concealed by a curvature in the ranges of the mountains... At the northern termination of this lovely valley, and immediately on the margin of the lake, lay the village of Templeton... (Cooper, 1896, p. 125, emphasis added)

This spot and the first prospect view it provides is memorized and cherished by the offspring of both the fictional and real family. For one of William Cooper's granddaughters-Susan Cooper, the views of the open lake enriched by its harmonious surroundings "are always pleasing: hills and forest, farms and groves, encircling a beautiful sheet of water," and they are "enjoyment enough for one day" (Cooper, 1968, p. 17). In the entry for April 9th Susan describes such an enjoyment brought in by the reflecting water as follows:

Standing on the hillside within the woods, we looked down beneath an archway of green branches, and between noble living columns of pine and hemlock, upon the blue waters below, as though we were gazing at them through the elaborate mouldings of a great Gothic window-a fine frame for any picture. Several boats were moving about, and there was a sparkling ripple playing in the sunshine, as though the waters enjoyed their freedom. (Cooper, 1968, p. 17, emphasis added)

Once again, the prospect view seen from the summit of a hill is got from here, though it might not be of Mount Vision on the eastern shore, which has held for the Coopers great importance. And the reflections in the surface of the lake are emphasized as well, which is imagined as "mouldings of a great Gothic window" or "a fine frame for any picture." This kind of view "Rooted in the gaze from above" (Johnson, 2007, p. 41) is also described in the entry for October 2nd, in which the reflecting properties of the lake as an elaborate mirror are featured as well:

Sat upon the cliffs enjoying the view. The day was perfectly still, the lake calm and placid, the reflection of its banks more than usually lovely in its clearness, and accuracy; the changing woods, each brilliant tree, the hills, farms, and buildings were all repeated with wonderful fidelity, and all the sweetness of the natural landscape. (Cooper, 1968, p. 209, emphasis added)

Nevertheless, this prospect view seen from the mountaintop is less approved in the last one of Cooper's leatherstocking romances-The Deerslayer. When writing this one more book, Cooper preferred a lower vantage point, for although there might be "the first feeling of satisfaction at commanding so many objects" by climbing up mountains, "Most views lose in the details what they gain by extent," namely, "those minuter points of beauty" might be "lost for the want of the profile in bird's eye prospects" (Nevius, 1976, p. 29) In Cooper's remark in another context: "Looking down from lofty heights astonishes, and, for a time, excites the feelings," however, "I cling to the opinion, that we most love the views, at which we are accustomed to gaze from the margin of quiet waters, or from the depths of valley" (cited by Nevius, 1976, p. 29). How did Cooper take mainly close-up views instead of a prospect one in The Deerslayer will be discussed in the next section.

\section{The Close-Up Views of the Glimmerglass in The Deerslayer}

The lake's "changing moods and symbolic importance as a 'Glimmerglass"” (MacDougal, 1989, p. 70) reflects the moral character of the protagonist named Deerslayer, whose responses to the lake when confronted unexpectedly with the scenery at it shows a Thoreauvian "transformation of his consciousness through attunement to nature," which is "essentially a process of joyful self-renew" (Barbour, 2004, p. 124). When he "broke suddenly into the brilliant light of the sun, on a low gravelly point, that was washed by water on quite half its outline" (p. 35), the lake strikes him and catches his full attentions at the first sight. This view that unexpectedly met his gaze is described as follows:

On a level with the point lay a broad sheet of water, so placid and limpid that it resembled a bed of the pure mountain atmosphere, compressed into a setting of hills and woods. Its length was about three leagues, while its breadth was irregular, expanding to half a league, or even more... its margin was irregular, being indented by bays, and broken by many projecting, low points. At its northern, or nearest end, it was bounded by an isolated mountain, lower land falling off east and west, gracefully relieving the sweep of the outline. Still the character of the country was mountainous; high hills, or low mountains, rising abruptly 
from the water, on quite nine tenths of its circuit. (p. 35)

Generally, this lake is featured in the form of an amphitheatre. The space concerning such a landscape is one "that is surrounded by high land in a circular slope" as well as "a circular building without a roof and with rows of seats that rise in steps around an open space" (Wehmeier, 2000, p. 38). Such a comparatively enclosed and independent space tends to arouse the sense of seclusion and "solemn solitude and sweet repose" which "were the most striking peculiarities of this scene," for "On all sides, wherever the eye turned, nothing met it but the mirror-like surface of the lake, the placid view of heaven, and the dense setting of woods" (p. 35). The same scene and atmosphere are illustrated elaborately in the ending paragraph of chapter two in The Deerslayer:

The spot was very lovely... the surface of the lake being as smooth as glass and as limpid as pure air, throwing back the mountains, clothed in dark pines, along the whole of its eastern boundary, the points thrusting forward their trees even to nearly horizontal lines, while the bays were seen glittering through an occasional arch beneath, left by a vault fretted with branches and leaves. It was the air of deep repose- the solitudes, that spoke of scenes and forests untouched by the hands of man-the reign of nature... (p. 46)

No doubt that "the hand of man had never yet defaced or deformed any part of this native scene, which lay bathed in the sunlight, a glorious picture of affluent forest grandeur, softened by the balminess of June, and relieved by the beautiful variety afforded by the presence of so broad an expanse of water" (p. 36). Here, the trees, flowers, hills and waters combine to form an Eden, an undeveloped virgin land which nevertheless might stimulate one's wild desire of occupation on the one hand, and the feeling of appreciation and reverence on the other. As an aggressive land speculator, William Cooper "habitually saw future fields and pastures and villages where trees and grasses and brush grew," which was "a tract of land he was angling to acquire" (Franklin, 2007, p. 2, 16). And, "proclaiming settlement an unmitigated good," he held the dominating social values of his contemporary frontiers - "Settlers gave order to the disorder of mere nature, thereby justifying their usurpation of Native American rights as well as their destruction of native plants and animals" (Franklin, 2007, p. 3). Thus, there would hardly be a sound man-nature relationship concerning such a wild land in a land speculator's eyes.

However, there is a positive aspect of the wild land, for as Thoreau's words revealed: "Life consists with Wildness. The most alive is the wildest" and "In wildness is the preservation of the world" (2001, pp. 239-240). Instead of considering nature as "the waste of the creation," Deerslayer treats "nature as a source of order," which should be wealthy of loves and respects and exclamations: "This is grand!- 'tis solemn!-_tis an edication of itself, to look upon!" (p. 36) For him who runs across Otsego Lake, "This is a sight to warm the heart!" (p. 37) His heart even swells with gratitude to the beneficent God: "everything left in the ordering of the Lord, to live and die according to his own designs and laws!" and "land and water alike stand in the beauty of God's providence!" (p. 37) Anyhow, how to name this lake basically depends on the properties of the landscape itself. Deerslayer "got to calling the place the 'Glimmerglass,' seeing that its whole basin is so often hinged with pines, cast upward to its face as if it would throw back the hills that hang over it" (p. 46). The lakescape "gave so much pure delight to one of his habits and turn of mind" (p. 46), the influences of this unexpected encounter on his self-knowledge of formulating a harmonious human relation to nature are easy to see:

Still, he felt, though it was unconsciously, like a poet also. If he found a pleasure in studying this large, and to him unusual opening into the mysteries and forms of the woods, as one is gratified in getting broader views of any subject that has long occupied his thoughts, he was not insensible to the innate loveliness of such a landscape neither, but felt a portion of that soothing of the spirit which is a common attendant of a scene so thoroughly pervaded by the holy cairn of nature. (p. 46)

Feeling "like a poet" is concerned with owning the eyes that "can integrate all the parts," for "when the mind is open to all the influences" and "all natural objects make a kindred impression," only through such eyes of a poet , "In their eternal calm, he finds himself "in a harmony with nature (Emerson, 2010, p. 4, 10). Here, the greatest delight which the lakescape ministered is suggestive of an occult relation between that hunter and the lake. Once established, this bond might be perceived at different time in a day.

Deerslayer's physical and inward journey starts on a "glorious June afternoon," when "The light air scarce descended as low as the bed of the lake, hovering over it, as if unwilling to disturb its deep tranquility, or to ruffle its mirror-like surface," while "the forests appeared to be slumbering in the sun, and a few piles of fleecy clouds had lain for hours along the northern horizon like fixtures in the atmosphere, placed there purely to embellish the scene" (p. 144). With the time passing by, the forests are still "sleeping in the deep repose of nature, the heavens were placid, but still luminous with the light of the retreating sun, while the lake looked more lovely and calm than it had before done that day," and once again, in Deerslayer's heart some mixed feelings are evoked by such a mystic and peaceful scene, which "was altogether soothing, and of a character to lull the 
passions into a species of holy calm" (p. 82). This calm arrives at its climax an hour later:

The lake was still placid and glassy, but the gloom of the hour had succeeded to the soft twilight of a summer evening, and all within the dark setting of the woods lay in the quiet repose of night. The forests gave up no song, or cry, or even murmur, but looked down from the hills on the lovely basin they encircled, in solemn stillness. (p. 90)

It is till this moment at this very spot that Deerslayer accomplishes the "transformation of his consciousness through attunement to nature" and the "process of joyful self-renew." Concerning the great significance of this interaction of man and nature, the elaborate description out of Cooper's genius is quoted at length:

It would be difficult to convey to the minds of those who have never witnessed it, the sublimity that characterizes the silence of a solitude as deep as that which now reigned over the Glimmerglass. In the present instance, this sublimity was increased by the gloom of night, which threw its shadowy and fantastic forms around the lake, the forest, and the hills. It is not easy, indeed, to conceive of any place more favorable to heighten these natural impressions, than that Deerslayer now occupied. The size of the lake brought all within the reach of human senses, while it displayed so much of the imposing scene at a single view, giving up, as it might be, at a glance, a sufficiency to produce the deepest impressions. (p. 106)

In addition to the repetition of some linguistic items, such as "difficult to convey" and "not easy, indeed, to conceive," the singularity of Deerslayer's experiences is also enhanced by his emphasis of the initial properties, for "this was the first lake Deerslayer had ever seen. Hitherto, his experience had been limited to the courses of rivers and smaller streams, and never before had he seen so much of that wilderness, which he so well loved, spread before his gaze" (p. 107). Even so, Deerlsayer's mind "was capable of portraying all its hidden mysteries, as he looked upon its leafy surface" (p. 107).

\section{Conclusion}

Multiple views of a lake are involved in perceiving and imagining its scenery, which combine to make a full picture and bring in rich experiences. Concerning the Glimmerglass, namely Otsego Lake, the prospect views of the lake at the mountain summit are frequently taken by its encounters with ravishment in the Coopers' lake writings ranging from William Cooper's wilderness narrative, James Cooper's The Pioneers and Home as Found to Susan Cooper's Rural Hours, which portray thoroughly an interconnected community and help the encounters to gain the sense of domination and somehow claim the role of conqueror, who nevertheless is still an outsider for the scenery. Meanwhile, the close-up views preferred in The Deerslayer can denote more immediate responses to the lakesape, and accordingly with more engagement and even immersion in the environment an encounter like Deerslayer might become an insider, who, with a "sympathy for mystic states" (Hodder, 2001, p. 21) experienced by Thoreau, might regain a sense of homecoming or dwelling as Wordsworth once gained. This process or state can be prompted by a "sweet view" of a lake with a particular reflecting property, which lies at the core of any author lake country.

As a preliminary study, this one has achieved its aim if it does offer a further insight into the modes of perceiving and imagining the lake scenery. However, there is still more that could or should be said, and a probe into the views of the lake at sunrise and sunset is such an instance.

\section{References}

Barbour, J. D. (2006). The Value of Solitude: The ethics and spirituality of aloneness in autobiography. Charlottesville, VA: University of Virginia Press.

Cooper, J. F. (1896). Home as Found. New York, NY: G. P. Putnam's Sons.

Cooper, J. F. (1993). The Deerslayer. New York, NY: Oxford University Press.

Cooper, J. F. (2005). The Last of the Mohicans. San Diego, CA: ICON Group International, Inc.

Cooper, J. F. (2007). The Pioneers. New York, NY: Signet Classics.

Cooper, S. F. (1968). Rural Hours. Oxford, England; New York, NY: Syracuse University Press.

Dwight, T. (1969). Travels in New England and New York (vol. 3). Cambridge, MA: The Belknap Press of Harvard University Press.

Emerson, R. W. (2010). Selected works of Ralph Walda Emerson. Shanghai: Shanghai World Books.

Franklin, W. (2007). James Fenimore Cooper: The early years. New Haven, CT: Yale University Press. https://doi.org/10.12987/yale/9780300108057.001.0001 
Gilpin, W. (2013). Observations, relative chiefly to picturesque beauty, made in the year 1772, on several parts of England, particularly the mountains, and lakes of Cumberland, and Westmoreland (vol. 1). New York, NY: Cambridge University Press.

Hess, S. (2012). Wordsworth and the ecology of authorship: The roots of environmentalism in nineteenth-century culture. Charlottesville, VA; London, England: University of Virginia Press.

Hess, S. (2016). Wordsworthshire and Thoreau country: Transatlantic landscape of genius. In P. Westover \& A. W. Rowland (Eds.), Transatlantic literature and author love in the nineteenth century (pp. 176-179). New York, NY: Palgrave Macmillan. https://doi.org/10.1007/978-3-319-32820-1_8

Hodder, A. D. (2001). Thoreau's ecstatic witness. New Haven, CT: Yale University. https://doi.org/10.12987/yale/9780300089592.001.0001

Johnson, M. (2007). Ideas of landscape. Malden, MA: Blackwell Publishing. https://doi.org/10.1002/9780470773680

MacDougal, H. C. (1989). Cooper's Otsego County: A bicentennial guide of sites in Otsego County associated with the life and fiction of James Fenimore Cooper, 1789-1851. Cooperstown, NY: New York State Historical Association.

MacDougal, H. C. (1998). Making a place historic: The Coopers and Cooperstown. Retrieved from https://jfcoopersociety.org/articles/INFORMAL/HUGH-HISTORIC.HTML

Nevius, B. (1976). Cooper's landscapes: An essay on the picturesque vision. London, England; Berkeley \& Los Angeles, CA: Oxford University Press.

Novak, B. (2007). Nature and culture: American landscape and painting, 1825-1875. New York, NY: University of California Press.

Philbrick, T. L. (1979). Cooper country in fiction. Originally published in James Fenimore Cooper: His Country and His Art, or Getting Under Way. Papers from the 1978 Conference at State University of New York College at Oneonta and Cooperstown, New York. Edited by George A. Test. (pp. 7-14). Retrieved from https://jfcoopersociety.org/articles/SUNY/1978SUNY-PHILBRICK.HTML

Siewers, A. K. (2019). Cooper's green world: Adapting ecosemiotics to the mythic eastern woodlands. Presented at the 17th Cooper Seminar, James Fenimore Cooper: His Country and His Art at the State University of New York College at Oneonta, July, 2009. Retrieved from https://jfcoopersociety.org/articles/SUNY/2009suny-siewers.html

Spector, S. J. (1977). Wordsworth's Mirror Imagery and the Picturesque Tradition. ELH, 44(1), 85-107. https://doi.org/10.2307/2872528

Thoreau, H. D. (2001). Henry David Thoreau: Collected essays and poems. New York, NY: Literary Classics of the United States, Inc.

Watson, N. J. (Ed.). (2009). Literary tourism and nineteenth-century culture. New York, NY: Palgrave Macmillan. https://doi.org/10.1057/9780230234109

Wehmeier, S. (Ed.). Oxford advanced learner's dictionary (6th ed.). Oxford, England: Oxford University Press.

\section{Copyrights}

Copyright for this article is retained by the author, with first publication rights granted to the journal.

This is an open-access article distributed under the terms and conditions of the Creative Commons Attribution license (http://creativecommons.org/licenses/by/4.0/). 